\title{
O IMPOSTO TERRITORIAL RURAL (ITR) COMO FERRAMENTA DA GESTÃO TRIBUTÁRIA
}

\author{
RURAL TERRITORIAL TAX AS A TOOL FOR TAX \\ MANAGEMENT
}

Tales Garcia Antunes

Mestrando no Programa de PósGraduação em Engenharia de Transportes e Gestão Territorial (PPGTG) Universidade Federal de Santa Catarina - UFSC. E-mail: talesantunes@hotmail.com

\section{RESUMO}

Este artigo tem como finalidade demonstrar aos gestores municipais que o mapeamento das áreas rurais, uma vez inserido no cadastro urbano, pode trazer como resultado direto a gestão plena do território e incremento de receita, através de convênios com o estado. A vulnerabilidade do sistema declaratório para tributação da propriedade rural também será apresentada, sistema em que o proprietário escolhe a alíquota do imposto que irá pagar, resultando em pagamento geralmente abaixo do que se deveria. Também a existência das ocupações em áreas públicas, que, por fraudes e ineficácia de fiscalização, por parte da União, são anexadas como territórios particulares, efeito da grilagem de terras no Brasil. Será demonstrado em forma de mapeamento temático o quantitativo das áreas de alguns estados brasileiros que possuem estabelecimentos rurais e o que os municípios estão deixando de arrecadar com esse imposto. E, finalizando este artigo, analisaremos como a gestão municipal pode gerir $100 \%$ do Imposto Territorial Rural (ITR) e utiliza-lo como incremento de renda na gestão de todo o território municipal.

Palavras-chave: Imposto rural. Gestão territorial. Cartografia Temática.

\section{ABSTRACT}

The purpose of this article is to demonstrate to municipal managers that the mapping of rural areas, once inserted in the urban cadaster, can result in full management of the territory and increment of revenue, through agreements with the state. The vulnerability of the declaratory system for rural property taxation will also be presented, a system in which the owner chooses the tax rate that he will pay, resulting in payment generally below what he owes. Also the existence of occupations in public areas, which, due to fraud and inefficiency of inspection, by the Union, are annexed as particular territories, effect of land grabbing in Brazil. It will be demonstrated in the form of a thematic mapping the quantitative of the areas of some Brazilian states that have rural establishments and what the municipalities are no longer collecting with this tax. At the end of this article, we will analyze how municipal management can manage $100 \%$ of the Rural Territorial Tax (ITR) and use it as an income increase in the management of the entire municipal territory.

Keywords: Rural tax. Territorial management. Thematic cartography. 


\section{INTRODUÇÃO}

A vulnerabilidade do Imposto Territorial Rural (ITR) no Brasil é consequência direta de uma falha no sistema de tributação, uma vez declaratório, ou seja, o proprietário escolhe a alíquota do imposto que deseja pagar. Além desse tipo de falha, que resulta em pagamento, geralmente abaixo do que deveria ser, há também as fraudes em relação à ocupação de terras, devido à falta de controle de áreas públicas que há no país. Com as novas técnicas de mapeamento do território e criação e manutenção constante do cadastro municipal, essa realidade poder ser ajustada.

\section{VULNERABILIDADE DO SISTEMA DECLARATÓRIO PARA TRIBUTAÇÃO DA PROPRIEDADE RURAL}

A vulnerabilidade do sistema ITR se dá justamente por ser declaratório, em que cada proprietário escolhe sua alíquota, facilitando as fraudes e pagamentos inadequados pela terra. Vilarinho descreve a cronologia do Imposto Territorial Rural no Brasil conforme sua implantação e as legislações.

a) 1879; instituído em todo o Império um imposto de $5 \%$ sobre as propriedades urbanas e rurais;

b) 1891; facultada aos estados - antigas províncias - a cobrança de um imposto territorial, não especificando se constituiria um imposto restrito â área urbana ou rural;

c) Constituição de 1934; surgi a distinção entre imposto territorial rural e urbano. A cobrança fica a cargo dos estados, sendo reafirmada nas Constituições de 1937 e 1946;

d) Emenda Constitucional de 1964; a cobrança do imposto foi transferida para a União;

e) Constituições de 1967 e 1969, o ITR passa a ser cobrado pelo Instituto Brasileiro de Reforma Agrária (IBRA);

f) 1970; cobrança do imposto foi transferida ao Instituto Nacional de Colonização e Reforma Agrária (INCRA);

g) Constituição Federal de 1988; o imposto retorna como competência da União. 


\section{O SISTEMA DECLARATÓRIO E AS FRAUDES QUANTO À OCUPAÇÃO DE TERRAS}

O fato do imposto sobre a propriedade na territorialidade rural ter sido historicamente declaratório é decisivo para um grande número de fraudes ocorridas em relação à ocupação de terras. A estrutura fundiária brasileira iniciou-se baseada em ocupação indiscriminada, sem ordenamento, o que resultou na situação presente, com grande número de propriedades estabelecidas por meio de grilagem, que ocorrem principalmente por três motivos:

(1) desconhecimento do Estado em relação às suas próprias terras, também chamadas terras devolutas, que faz com que ainda nos dias atuais se possa ocupar e mesmo manter atividades econômicas em terras públicas sem que as autoridades competentes consigam tomar conhecimento;

(2) quase absoluta falta de fiscalização no meio rural, onde o INCRA - Instituto Nacional da Colonização e Reforma Agrária, a Polícia Federal, o IBAMA - Instituto Brasileiro do Meio Ambiente e todos os demais órgãos com algum tipo de competência para tal se resguardam atrás da falta de contingente e da burocracia institucionalizada;

(3) talvez mais grave, é a possibilidade mínima da punição, já que mesmo diante de fiscalização nos casos flagrantes dificilmente os invasores são responsabilizados (ARAUJO, 2014. p97).

Por esses três motivos, têm-se fraudes em ocupação de forma irregular. Mas não é a única fraude que ocorre em áreas rurais, pois, mesmo em terras legalizadas, devido ao fato do sistema ser declaratório, segundo Brasil (2010), em alguns casos, os proprietários de terras escolhem em que alíquota desejam se encaixar, declarando de forma fraudulenta em relação à ocupação na sua propriedade. O ITR é definido por alíquotas que sofrem progressão em relação ao tamanho do imóvel e regressão em relação à ocupação.

Dessa forma, também incentivados pela falta de fiscalização do INCRA e da Receita Federal, os proprietários tendem a declarar maior ocupação da terra, reduzindo a alíquota e, portanto, o próprio imposto a ser pago. Como consequência, o proprietário acaba sendo beneficiado duplamente, pois, dessa forma, ainda evita o enquadramento do imóvel como candidato à desapropriação para fins de reforma agrária (ARAUJO, 2014).

Com um sistema declaratório tão falho, é comum ver inúmeras apropriações irregulares em cima de terras públicas. Dentre esses, pode-se citar as grilagens de terra em todo o país até 1999, quando dezenas de milhões de hectares de terras foram detidas irregularmente por particulares. O Incra está mapeando a estrutura fundiária do país de modo a localizar, um a um, os casos de fraude e falsificação de títulos de propriedade de terras. A grilagem é um dos mais poderosos instrumentos de domínio e concentração fundiária no meio 
rural brasileiro. Em todo o país, o total de terras sob suspeita de serem griladas é de aproximadamente 100 milhões de hectares - quatro vezes a área do Estado de São Paulo (BRASIL, 1999).

O termo grilagem diz respeito a toda ação ilegal que objetiva a transferência de terras públicas para o patrimônio de terceiros, que tem seu início em escritórios e se consolida no campo mediante a imissão na posse de terras.

\begin{abstract}
A grilagem de terras acontece normalmente com a conivência de serventuários de Cartórios de Registro Imobiliário que, muitas vezes, registram áreas sobrepostas umas às outras - ou seja, elas só existem no papel. Há também a conivência direta e indireta de órgãos governamentais, que admitem a titulação de terras devolutas estaduais ou federais a correligionários do poder, a laranjas ou mesmo a fantasmas pessoas fictícias, nomes criados apenas para levar a fraude a cabo nos cartórios. Depois de obter o registro no cartório de títulos de imóveis, o fraudador repetia o mesmo procedimento no Instituto de Terras do Estado, no Cadastro do Incra e junto à Receita Federal. Seu objetivo era obter registros cruzados que dessem à fraude uma aparência de consistente legalidade. Ao contrário do que ocorre em outros países, no Brasil não existem registros especiais específicos para grandes áreas. Os dados dos cadastros federal e estaduais não estão cruzados e o cadastro federal, pela atual legislação, é declaratório. A correção (fiscalização) sobre os cartórios deixa a desejar (BRASIL, 1999).
\end{abstract}

Alguns casos de imóveis comprovadamente fraudados em estados brasileiros serão descritos na Tabela 1, totalizando uma extensão aproximada a 100 milhões de hectares. Conforme Brasil (1999), esse é o primeiro resultado parcial do levantamento que o Incra vem realizando em todos os Estados Brasileiros. Alguns deles não estão ainda contemplados alguns porque as respectivas pesquisas ainda não foram concluídas; outros não padecem de forma aguda do mal do latifúndio, como é o caso de Santa Catarina, por exemplo.

Tabela 1- Quantidade de áreas que tiveram seus cadastros cancelados pelo Incra

\begin{tabular}{llll}
\hline $\mathbf{N}^{\circ}$ & UF & $\mathbf{N}^{\circ}$ DE IMÓVEIS & ÁREA (ha) \\
$\mathbf{1}$ & AC & 90 & 3.593 .342 \\
$\mathbf{2}$ & AL & 3 & 41.004 \\
$\mathbf{3}$ & AM & 187 & 18.905 .002 \\
$\mathbf{4}$ & AP & 15 & 813.978 \\
$\mathbf{5}$ & BA & 255 & 5.749 .659 \\
$\mathbf{6}$ & CE & 11 & 153.132 \\
$\mathbf{7}$ & ES & 6 & 159.622 \\
$\mathbf{8}$ & GO & 75 & 1.306 .363 \\
$\mathbf{9}$ & MA & 153 & 4.087 .075 \\
$\mathbf{1 0}$ & MG & 138 & 2.635 .464 \\
$\mathbf{1 1}$ & MS & 363 & 7.211 .831 \\
$\mathbf{1 2}$ & MT & 960 & 22.779 .586 \\
$\mathbf{1 3}$ & PA & 422 & 20.817 .483 \\
$\mathbf{1 4}$ & PE & 1 & 21.850 \\
\hline
\end{tabular}




\begin{tabular}{llll}
\hline $\mathbf{1 5}$ & PI & 128 & 2.965 .724 \\
$\mathbf{1 6}$ & PR & 19 & 584.194 \\
$\mathbf{1 7}$ & RJ & 2 & 23.423 \\
$\mathbf{1 8}$ & RN & 4 & 66.977 \\
$\mathbf{1 9}$ & RO & 56 & 1.381 .623 \\
$\mathbf{2 0}$ & RR & 9 & 219.864 \\
$\mathbf{2 1}$ & RS & 10 & 113.183 \\
$\mathbf{2 2}$ & SC & 1 & 10.664 \\
$\mathbf{2 3}$ & SP & 40 & 2.114 .539 \\
$\mathbf{2 4}$ & TO & 117 & 2.865 .005 \\
\hline TOTAL & & 3.065 & 93.620 .587 \\
\hline
\end{tabular}

Fonte: Adaptada do Incra, 1999.

Segundo dados do Livro Branco de Grilagem de Terras no Brasil (BRASIL, 1999), o estado do Amazonas possui 55 milhões de hectares com indícios de grilagem. Desse total, 18 milhões de hectares já tiveram seus registros cancelados em decorrência de ações movidas pelo Incra, sendo as terras revertidas ao patrimônio da União. No Pará, ao menos 9 milhões de hectares foram vendidos de forma irregular, pois as terras eram públicas.

No estado do Acre, a existência de cerca de 1,6 milhões de hectares em áreas sobrepostas, com a junção de matrículas e presunção de registros indevidos. No Amapá, em apenas uma área, tem 65.793 ha (hectares) irregulares. O Incra está ajuizando ação para desconstituir os registros. Em Rondônia, existem falhas nos registros de alguns imóveis, e o Incra está propondo à Justiça nulidade de registros. Ao menos duas propriedades $(21.109$ ha e 16.074ha) estão irregulares. No estado de Goiás, ao menos duas propriedades, com 12.100ha e 62.635ha, só existem no papel, pois elas não foram encontradas em campo.

Em São Paulo, ao menos uma área com 193.600ha está com escritura fraudulenta. Ela está sob ação discriminatória (que visa recuperação para o Poder Público). No Paraná, nos anos de 1950, o Governo do Estado iniciou um processo de colonização de terras no estado, mas sem nenhum tipo de ordenação ou registro e em meados 1970, cerca de meio milhão de hectares foram desapropriados pelo INCRA.

Atualmente, veem-se muitas fraudes com relação ao Incra. Segundo TCU (2016), em abril de 2016 houve outro escândalo de fraudes, em que o Tribunal de Contas da União determinou a paralisação do programa de reforma agrária no país. Os auditores encontraram milhares de irregularidades. Segundo as investigações, até mortos receberam terras ou recursos do programa. A medida cautelar emitida pelo tribunal decorre de uma auditoria que identificou aproximadamente 600 mil beneficiários irregulares do programa, dentre os quais alguns serão apresentados na Tabela 2. 
Tabela 2 - Registros de beneficiários do programa de reforma agrária com indícios de irregularidades

\section{Aprox. 600 mil beneficiários}

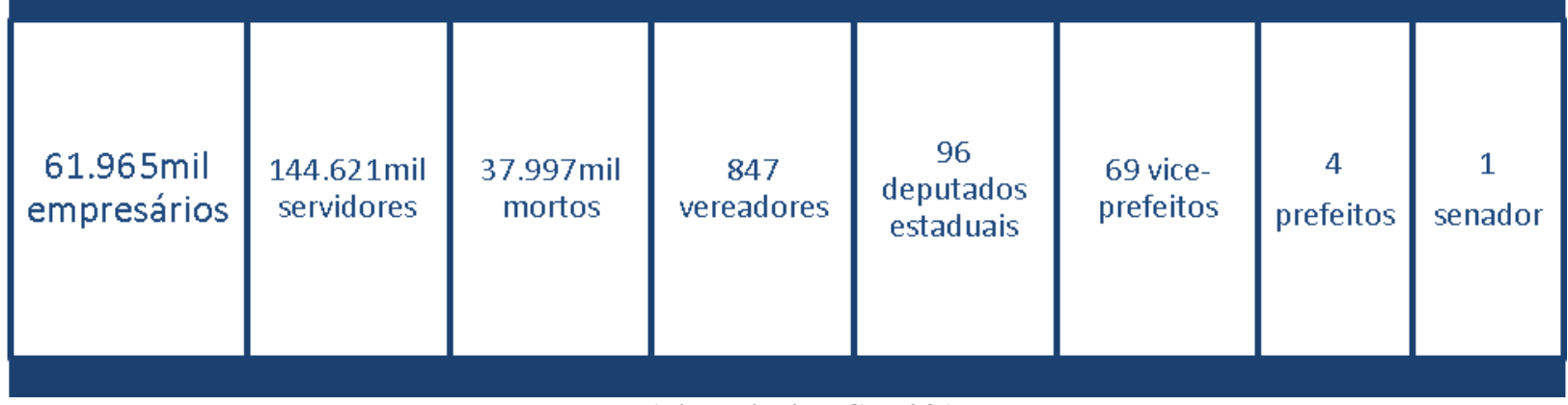

Fonte: Adaptada de TCU, 2016.

Todos são proibidos por lei de entrar no programa de reforma agrária, que deveria atender famílias com renda de até três salários mínimos e que lidam diretamente com a terra. Os nomes suspeitos estão em sigilo até o fim do processo.

Um avanço devido à preocupação na ocupação de áreas irregulares vem do Distrito Federal, onde o governador Rodrigo Rollember anunciou em março de 2016 um pacote com cinco medidas para a prevenção de ocupação de terras em DF. E, dentre essas medidas, há um conjunto de novos instrumentos de monitoramento territorial.

Segundo Agefis (2016) o seu Mapa de combate a grilagem e ocupações irregulares trata-se de um sistema de rastreamento por satélite realizado de 15 em 15 dias que será utilizado no combate à ocupação irregular de terras, com um mapa digital que mostrará quais regiões são alvos frequentes da ação de grileiros. A ferramenta é uma parceria entre a Agência de Desenvolvimento do Distrito Federal (Terracap) e a Agência de Fiscalização (Agefis). O mapa, relatado na Figura 1, servirá para ações imediatas, evitando a consolidação de novos assentamentos.

Figura 1 - Mapa de combate à grilagem em áreas do DF 


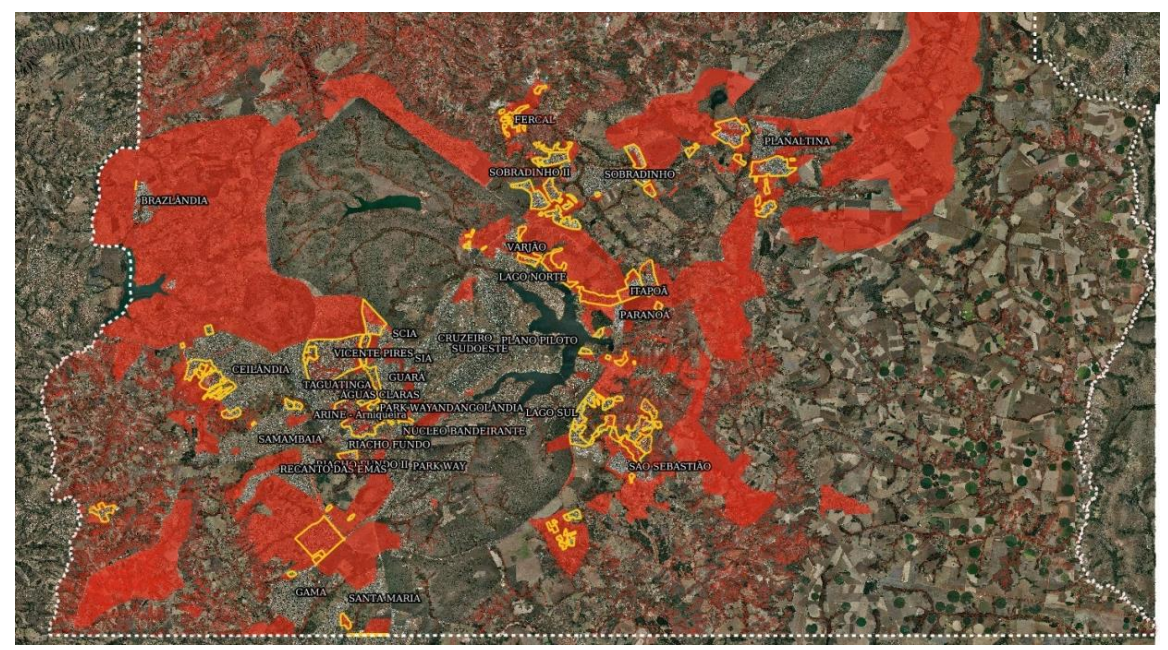

Fonte: Agefis, 2016.

O mapeamento temático demonstra que as áreas em vermelho serão desapropriadas e demolidas por serem áreas devolutas, e as em amarelo são áreas passíveis de regularização. A adoção de novas tecnologias é muito útil ao estado, pois, com monitoramento efetivo, o combate à ocupação irregular tende a ser mais efetivo.

O mapeamento temático permite quantificar as áreas a se intervencionar, bem como as áreas a serem regularizadas.

\section{CADASTRO RURAL E A GESTÃO FEDERAL}

Criado pelo Estatuto da Terra (Lei n. 4.504/1964), sob responsabilidade do IBRA (Instituto Brasileiro de Reforma Agrária) e do INDA (Instituto Nacional do Desenvolvimento Agrário), o Cadastro Rural sempre foi de competência federal. Para o governo federal, através desse cadastro se conheceriam:

(1) as condições vigentes na estrutura fundiária das várias regiões do País;

(2) as condições de efetiva distribuição e concentração da terra e do regime de domínio e posse vigentes nas várias regiões do País;

(3) as condições de uso temporário da terra, vigentes nas várias regiões do País;

(4) as disponibilidades de áreas apropriadas aos programas de Reforma Agrária e Colonização e a situação dos posseiros e ocupantes de terras públicas; e finalmente;

(5) os dados e elementos para orientar os órgãos de assistência técnica e de crédito na formulação de planos de assistência ao produtor rural (NASCIMENTO, 2007).

A evolução histórica do Cadastro Rural no Brasil teve início antes mesmo de sua criação como Cadastro Único, em 1972. Para Loch (2007a), a Lei 601 de 1850 foi o marco inicial do cadastro, uma vez que se passou a descriminar as terras públicas e as privadas quando se iniciou a preocupação com o registro públicos das terras. No entanto, não recebeu 
nenhuma menção como cadastro técnico, o que somente veio a acontecer em 1964, com a criação do Estatuto da Terra, Lei 4504, de novembro de 1964. E, em 1965, iniciou-se o cadastro. A seguir, uma breve trajetória até a legislação atual de cadastro:

a) O cadastro iniciou em 1965, na Semana da Terra, quando foram criadas as UMC - Unidades Municipais de Cadastramento mediante convênios com as prefeituras. Foram cadastradas, então, mais de três milhões de imóveis.

b) O INCRA foi criado em 1970, como fusão do IBRA com o INDA, e recebeu a competência de cuidar do cadastro rural;

c) A Lei $\mathrm{n}^{\circ}$ 5.868/72, posteriormente regulamentada pelo Decreto $\mathrm{n}^{\circ} 72.106 / 73$, instituiu o Sistema Nacional de Cadastro Rural (SNCR), que compreendia: (1) Cadastro de Imóveis Rurais; (2) Cadastro de Proprietários e Detentores de Imóveis Rurais; (3) Cadastro de Arrendatários e Parceiros Rurais; e, (4) Cadastro de Terras Públicas. A competência foi atribuída ao INCRA o que significava criar, organizar e manter os sistemas de informação (identificação, cartografia, informática, etc.), de valoração (sistema de preços de terras) e tributação dos imóveis rurais. Também ficava estabelecida a revisão periódica geral a cada cinco anos e a emissão dos CCIR - Certificado de Cadastro do Imóvel Rural.

d) Em 1990 a Lei $n^{\circ}$ 8.022/1990 transfere a competência da administração das receitas antes arrecadadas pelo INCRA, leia-se ITR, para a então denominada Secretaria da Receita Federal, hoje Receita Federal do Brasil (RFB), e assim possibilita a existência de dois cadastros rurais nacionais, com funções distintas (tributária e fundiária), independentes e administrados separadamente, segundo a finalidade de cada órgão gestor.

e) E após, com a publicação da Lei n ${ }^{\circ}$ 10.267/2001 esta, promove grandes mudanças na estrutura do cadastramento de imóveis rurais pela adoção do georreferenciamento e utilização de coordenadas e unifica os cadastros dividindo as competências e obrigando a troca de informações entre a Receita Federal, o INCRA e os registros dos cartórios de imóveis. (LOCH, 2007b).

E atualmente o cadastro continua sob gestão federal juntamente com o Incra, este é responsável pela físcalização de terras públicas e georreferenciamento de propriedades irregulares, conforme a Lei $\mathrm{n}^{\circ} 10.267$, na qual objetiva o conhecimento das poligonais de cada propriedade, em um sistema único, evitando a sobreposição de áreas, evitando assim as ocupações irregulares.

\section{O SISTEMA DECLARATÓRIO E A VULNERABILIDADE DO ITR}

Dentre os impostos de competência da União, de acordo com o art. 153, da Constituição Federal de 1988, seção III, item VI, está o Imposto Territorial Rural (ITR), instituído pela Lei n. 9.393, de 19 de dezembro de 1996, art. $1^{\text {o }}$; Decreto n. 4.382, de 19 de setembro de 2002, e incidente sobre os imóveis localizados fora das áreas urbanas dos municípios. A alíquota é maior para propriedades de maior área e baixo grau de utilização, de modo a desestimular os grandes latifúndios improdutivos (Receita Federal). 
O sistema se dá de forma declaratória através de formulário, não sendo possível, por parte da Receita Federal, uma análise mais criteriosa da veracidade das informações. O fator gerador do ITR é a propriedade rural, o domínio útil ou a posse do imóvel, localizado fora da zona urbana delimitada legalmente pelo município, tendo sua vigência anual.

É existente dentro das classificações dos imóveis rurais uma faixa com imunidade do imposto, da qual nos interessa particularmente a pequena gleba rural, a qual se define, segundo o relatório de 2017 sobre as principais dúvidas para a declaração do ITR junto à Receita Federal detalha:

A pequena gleba rural, 100ha, se localizado em município compreendido na Amazônia Ocidental ou no Pantanal mato-grossense e sul-mato-grossense; 50ha, se localizado em município compreendido no Polígono das Secas ou na Amazônia Oriental; 30ha, se localizado em qualquer outro município, desde que a explore o proprietário, titular do domínio útil ou possuidor a qualquer título que não possua qualquer outro imóvel, rural ou urbano, vedado arrendamento, comodato ou parceria. (Brasil, 2017)

Uma das vulnerabilidades do sistema declaratório do ITR está no fato de a receita federal colocar como responsável pelo crédito tributário a titularidade do imóvel sem prévia fiscalização dos dados informados, ou constatação por meio cartorário do atual proprietário.

Balata (1996) considera a arrecadação do ITR “inexpressiva e desprezível” diante das possibilidades não aproveitadas de receitas oferecidas pela grandiosidade territorial do País. Ele também estima que a cobrança mais adequada dos cadastros já realizados poderia gerar uma receita de mais de $\$ \mathrm{R} 4$ bilhões, e com um recadastramento pleno mais de $\mathrm{R} \$ 10$ bilhões.

Balata (1996) também faz um comparativo de que em países com regime fiscal mais
eficiente o imposto sobre a terra varia de $3 \%$ á $5 \%$ da carga tributária, no Brasil se o
imposto fosse corretamente taxado poder-se-ia render valores de $\mathrm{R} \$ 4,5$ á $\mathrm{R} \$ 7,5$
bilhões ano. O economista atribui essa defasagem à sonegação, porque a autoridade
tributária deixa a cargo do proprietário o preenchimento do Documento de
Informação e Apuração do ITR (DIAT), pelo qual o contribuinte informa o valor do
tributo que deve pagar ou não pagar. Além disso, existem no Brasil entre 4,5 a 5
milhões de imóveis rurais, mas só estão cadastrados cerca de 3,1 milhões,
totalizando uma área de terra ocupada de 331.364 .012 hectares. Mas existe, segundo
estimativas, uma área ocupada e não cadastrada de 513.754 .888 hectares. Daí o
cálculo do economista de que é possível arrecadar cerca de $\mathrm{R} \$ 10$ bilhões de
impostos sobre a terra.

As Figura 2 a Figura 7 demonstram o mapa temático relativo a unidades rurais estabelecidas nos estados de Santa Catarina, Rio Grande do Sul e Mato Grosso do Sul utilizadas aqui para representar grande quantidade de latifúndios e faixa de pagamento do ITR. Esses mapeamentos foram desenvolvidos pelo sistema WebCart do IBGE, em sua versão 
Beta, ferramenta simplificada para a criação de cartogramas a partir dos dados contidos no canal cidades.

Figura 2 - Mapa das unidades de estabelecimentos agropecuários do estado de Santa Catarina

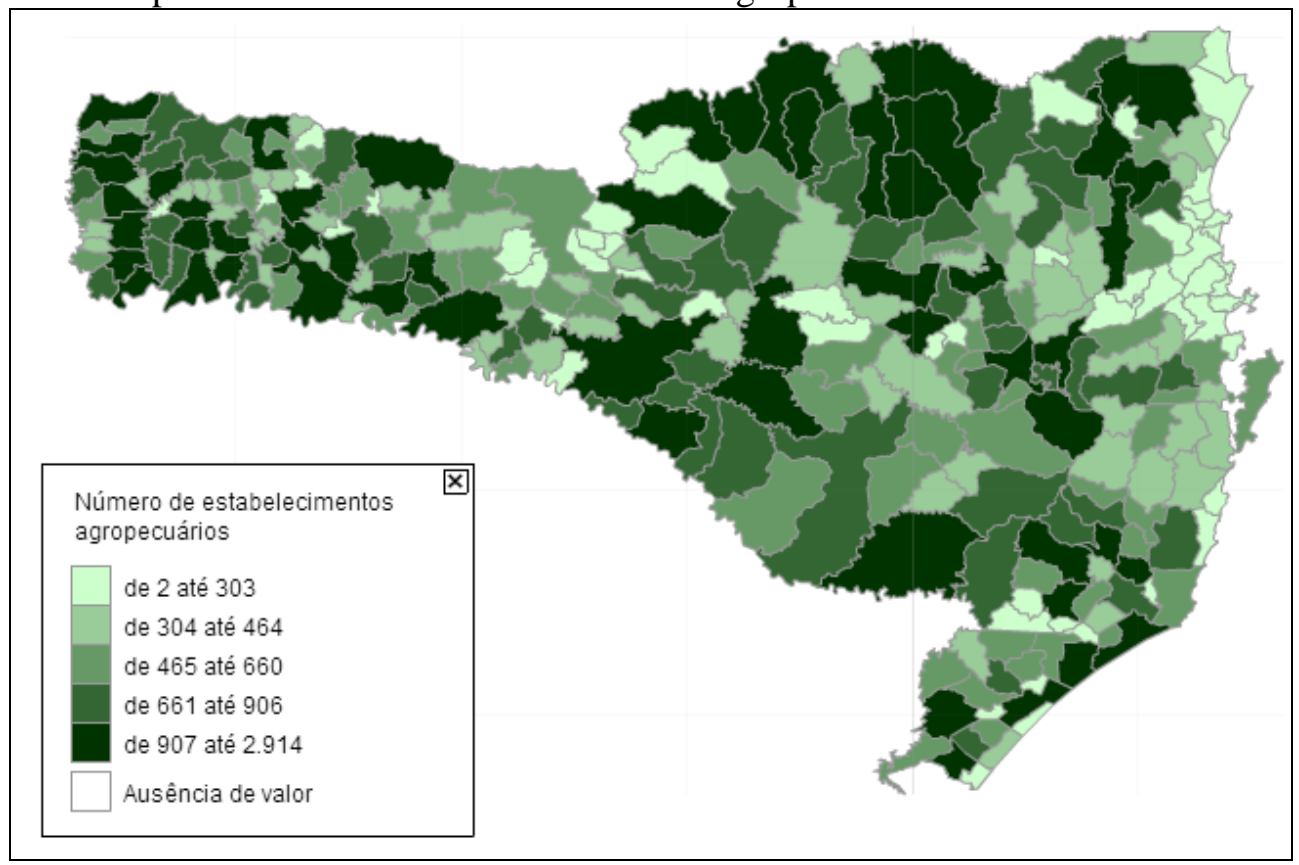

Fonte: Adaptada de WebCarta, IBGE

Figura 3 - Mapa dos valores médios de ITR para o estado de Santa Catarina

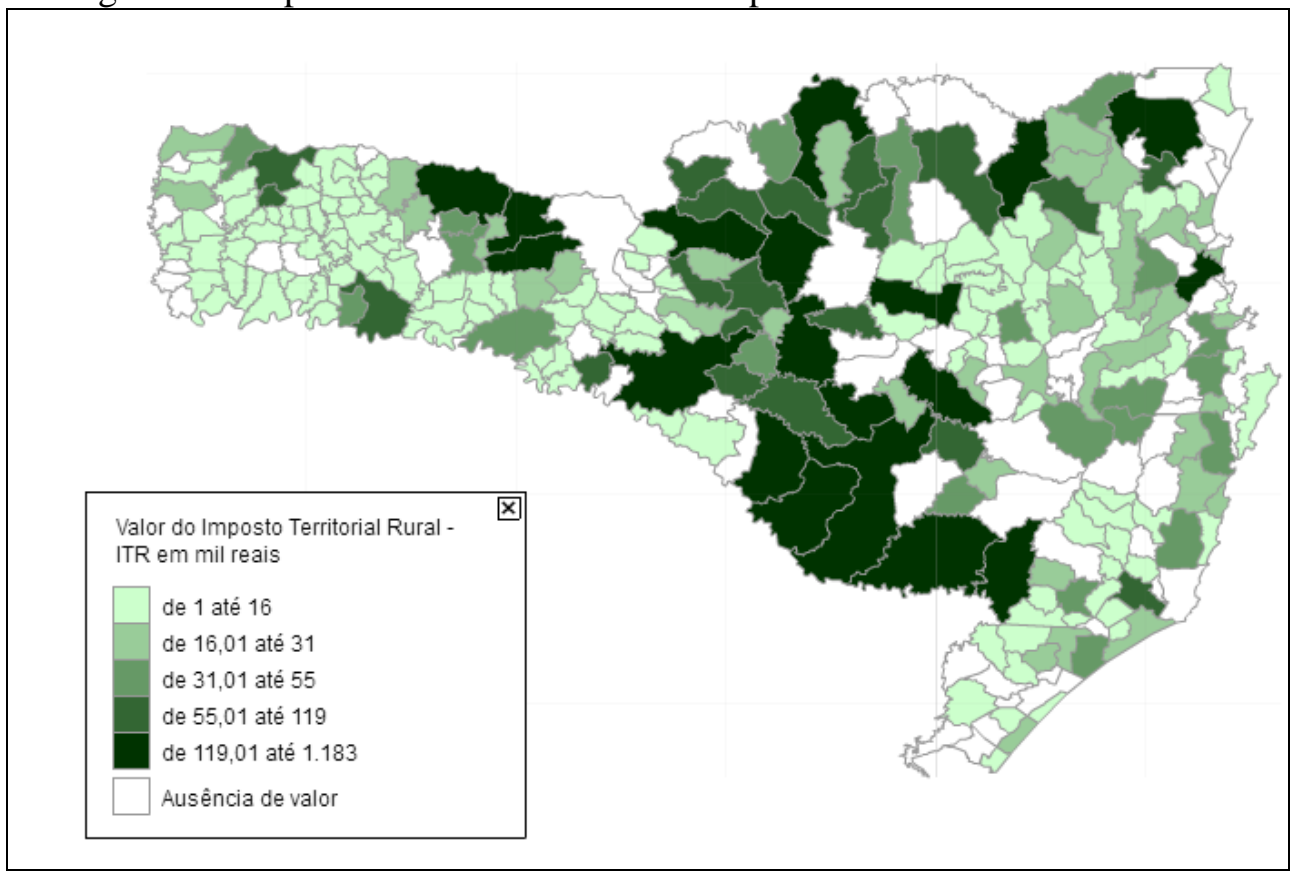

Fonte: Adaptada de WebCarta, IBGE

O que vale ressaltar nesses mapeamentos é a falta de maiores informações, principalmente aos declaratórios do ITR. Em campo descrito como ausência de Valor, em concordância com Balata (1996), descreve a falta do cadastramento das unidades rurais e dos sistemas de fiscalização das informações declaratórias do ITR. 
Revista Tecnologia e Ambiente, v. 24, 2018, Criciúma, Santa Catarina/SC ISSN Eletrônico 2358-9426 e ISSN Impresso 1413-8131

Figura 4 - Mapa das unidades de estabelecimentos agropecuários do estado do Rio Grande do Sul

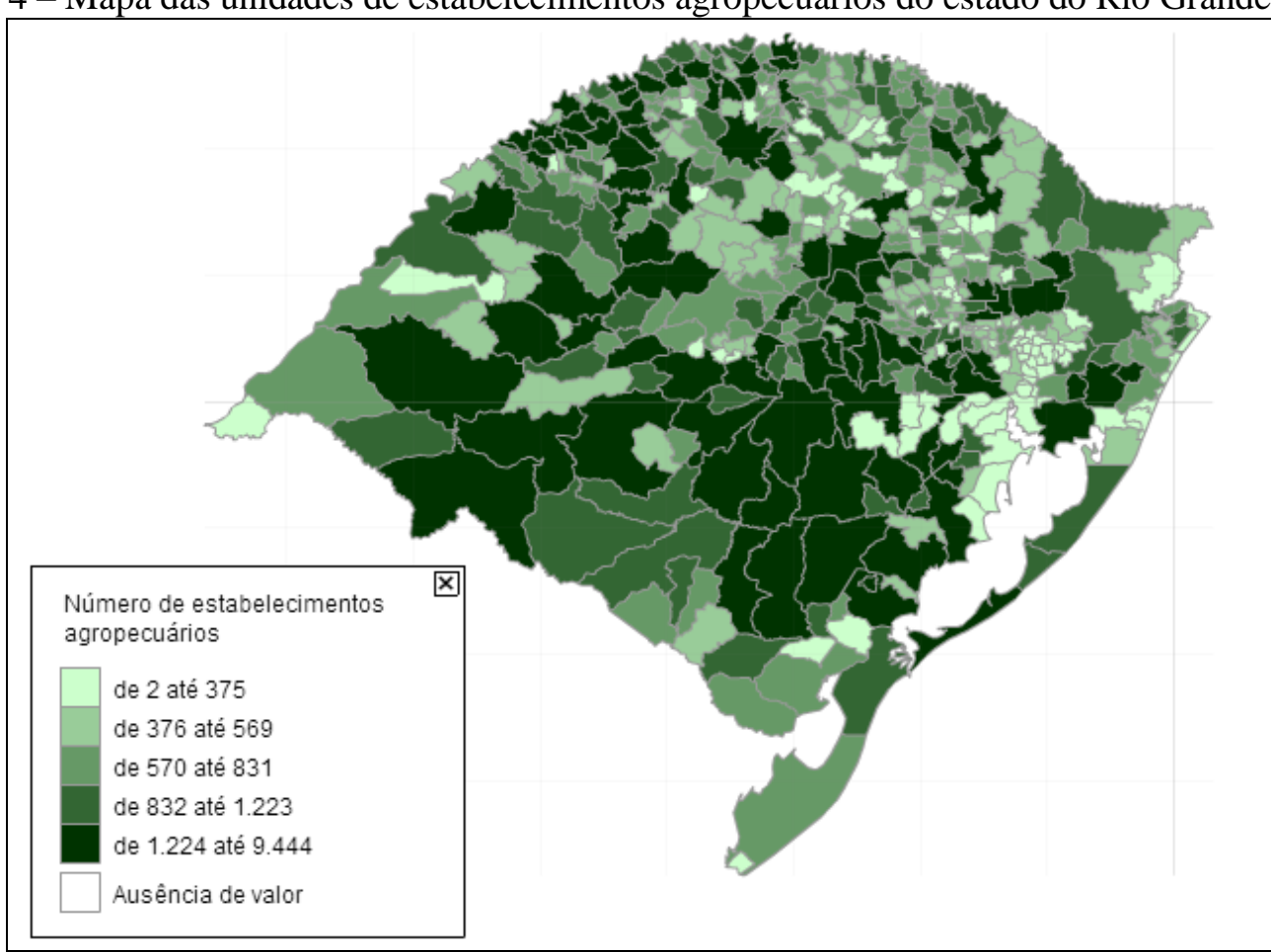

Fonte: Adaptada WebCarta, IBGE

Figura 5 - Mapa dos valores médios de ITR para o estado do Rio Grande do Sul

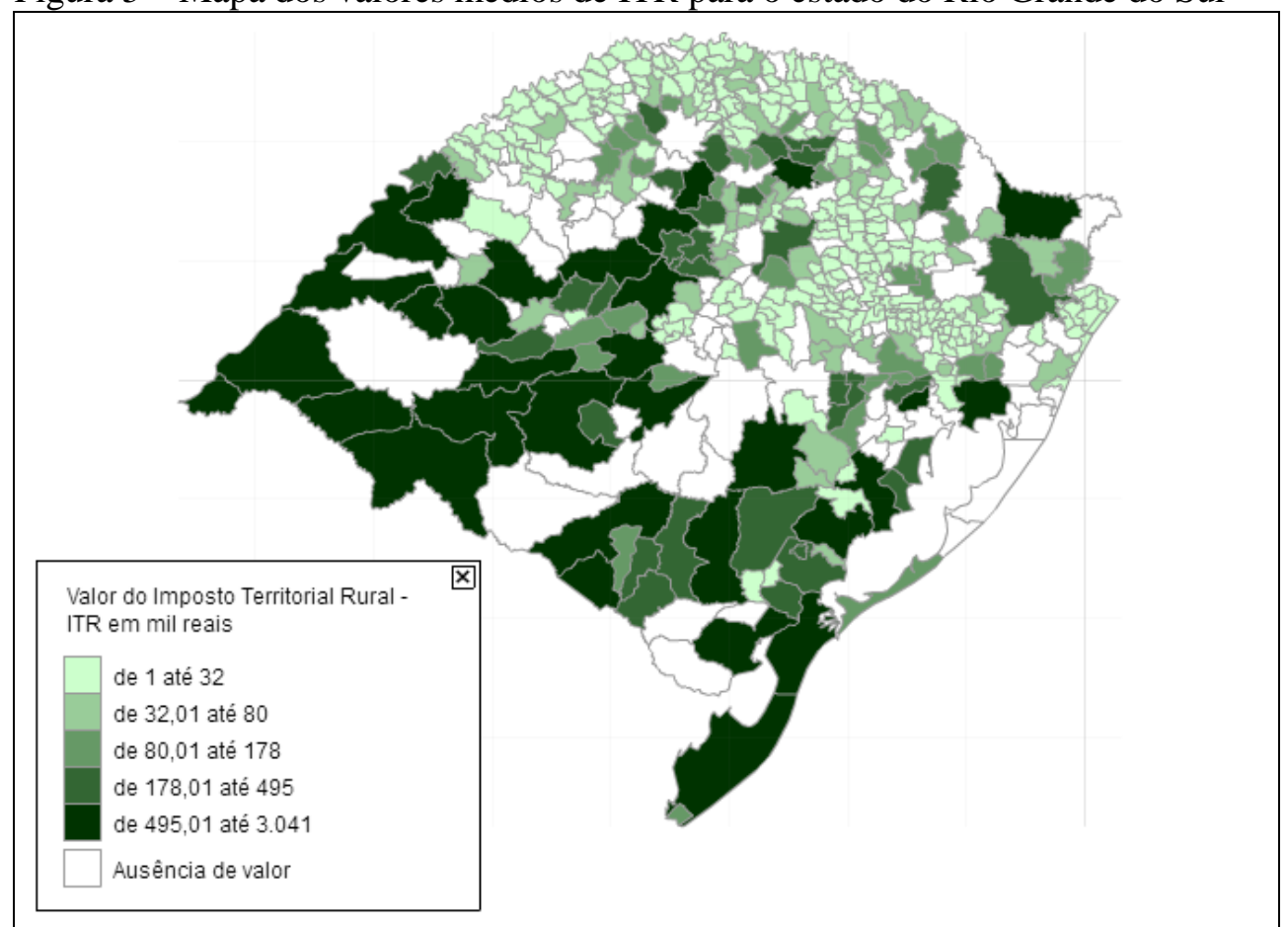

Fonte: Adaptada de WebCarta, IBGE 
Figura 6 - Mapa dos valores médios de ITR para o estado do Rio Grande do Sul

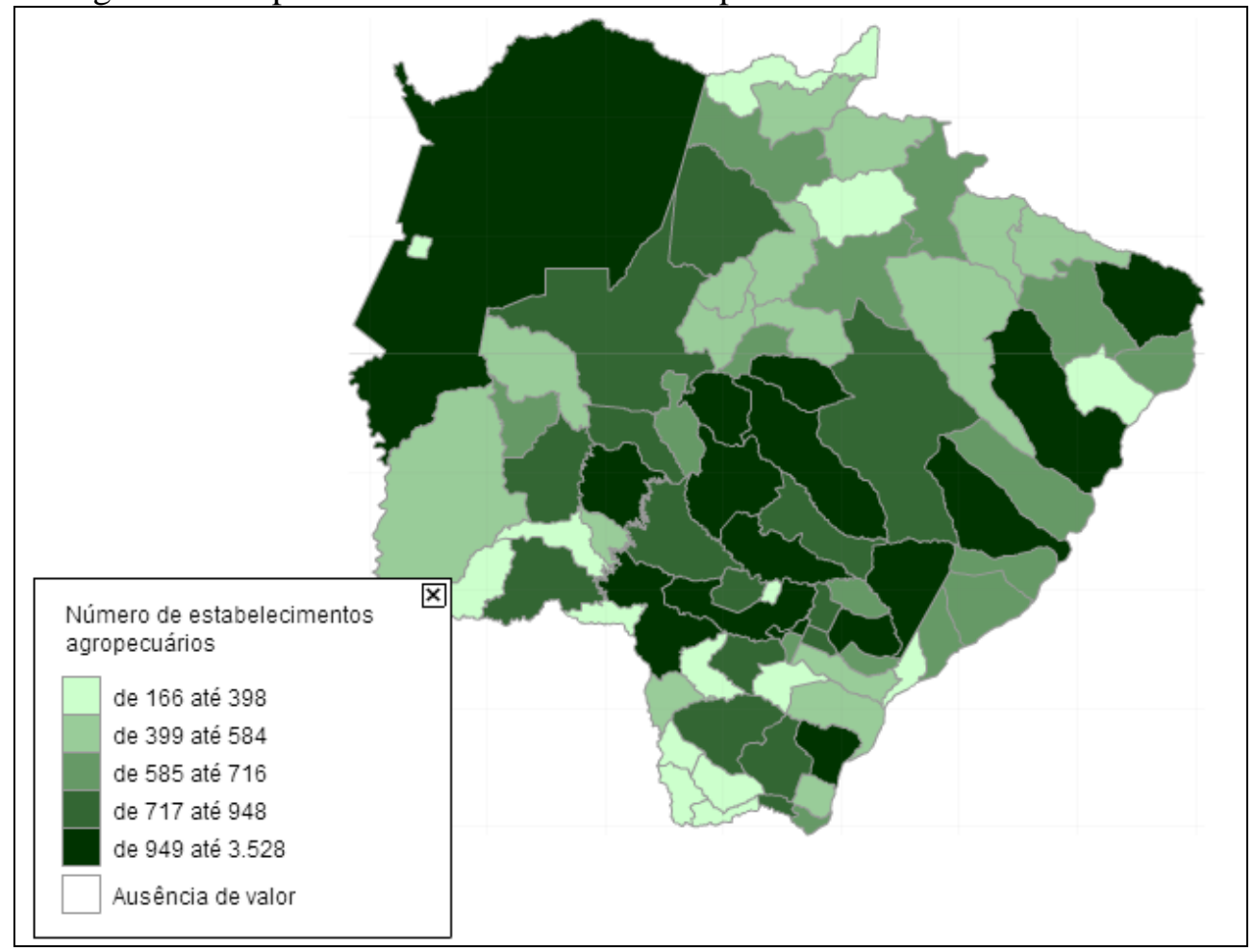

Fonte: Adaptada de WebCarta, IBGE.

Figura 7- Mapa dos valores médios de ITR para o estado do Mato Grosso do Sul

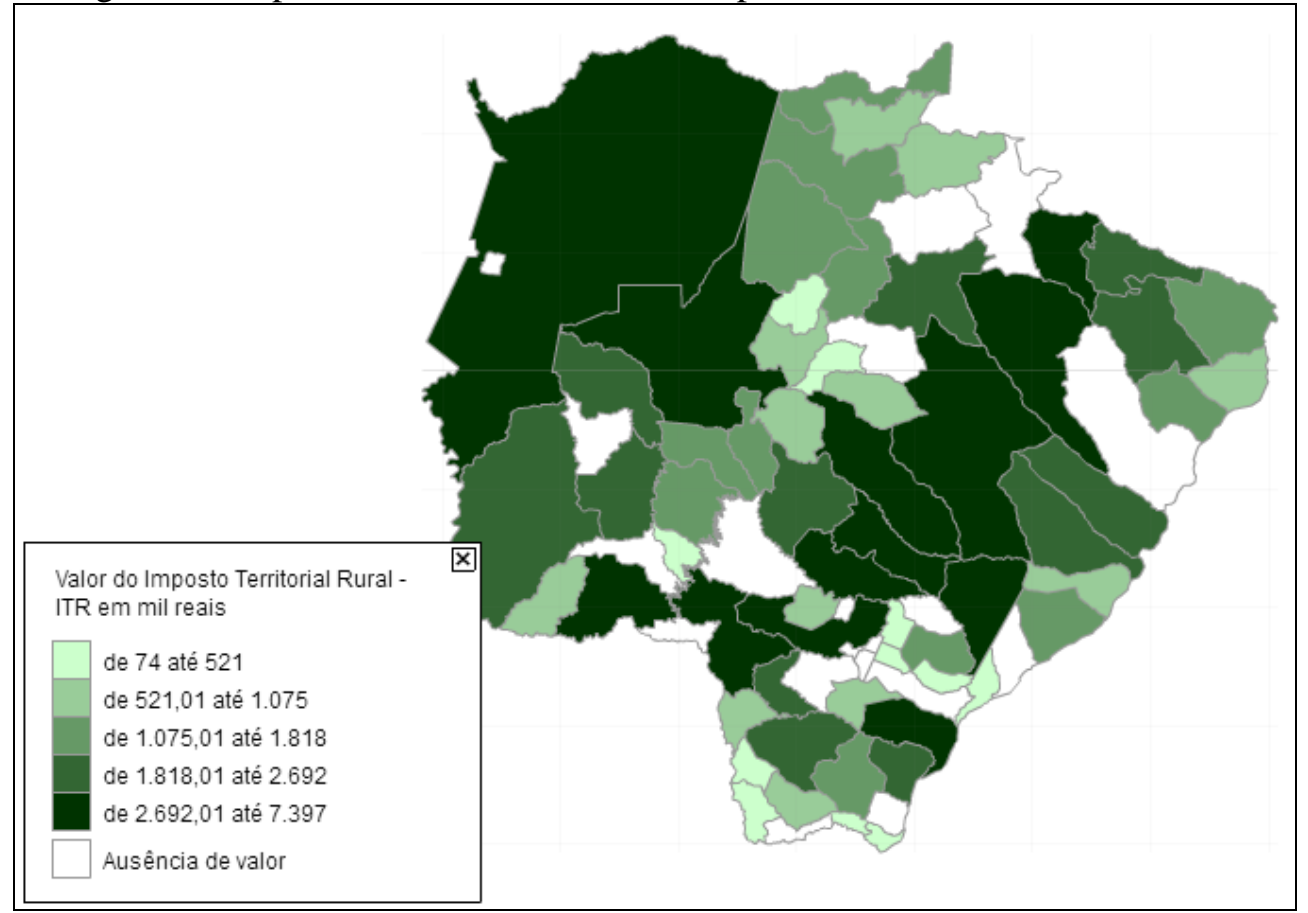

Fonte: Adaptada de WebCarta, IBGE.

Além dos aspectos culturais dos tributos sobre a terra no país, essas manobras passam invariavelmente pela declaração de dados incorretos, em vista do caráter autodeclaratório associado ao pagamento do ITR. Reydon e Plata (1996) evidenciam que essas declarações 
induzem às alíquotas menores, devido ao grau de utilização informado pelos proprietários, cuja fiscalização é praticamente inexistente:

[...] pode-se evidenciar que uma importante causa da baixa arrecadação é o fato de que a grande maioria dos proprietários de terras $(86,9 \%)$ declarou que atingiam mais de $80 \%$ de utilização das terras. [...] O próprio Incra no seu cadastro de 1992 indica que o grau de utilização médio das terras no país atingia $59,1 \%$ das terras, o que comparado com os $86,9 \%$ das declarações do ITR mostra uma boa parte da evasão.

Os dados mostram que se conhece o tamanho do descompasso existente entre a burocracia institucional e a situação de fato desses imóveis e ainda reforça o problema do atual fluxo de apuração do ITR, o qual não institui mecanismos para inibir a incompatibilidade das declarações com a realidade produtiva desses imóveis.

Vilarinho (1989, p. 118) detalha que o INCRA nunca exerceu quaisquer fiscalizações que viessem a averiguar as declarações que lhe são entregues. Com isso, tem-se permitido aos proprietários omitir de $40 \%$ a $70 \%$ da área de seus imóveis para efeito de tributação.

Destaca-se na Figura 8 o formulário declaratório no qual o proprietário declara a distribuição das áreas ocupadas pelo imóvel (preservação permanente, reserva legal, benfeitorias, interesse ecológico, tributáveis) Documento de Informação e Apuração do ITR (DIAT).

Figura 8 - Exemplo de preenchimento do item 10 do DIAT 10. DISTRIBUIÇÃO DA ÁREA DO IMÓVEL RURAL

Áreas em hectares

Preencha o campo 37 caso informe alguma área nos campos 02 a 08 deste quadro

(utilize uma casa decimal)

\begin{tabular}{|c|c|c|c|}
\hline Área total do imóvel (igual ao campo 02 do quadro 2) & 01 & $2|2| 8$ & \\
\hline Área de preservação permanente & 02 & $1 \quad 5$ & \\
\hline Área de reserva legal & 03 & $14 \mid 5$ & \\
\hline Área de reserva particular do patrimônio natural (RPPN) & 04 & 1 & \\
\hline Área de interesse ecológico & 05 & 1 & \\
\hline Área de servidão florestal ou ambiental & 06 & $\perp$ & \\
\hline Área coberta por florestas nativas & 07 & $\perp$ & \\
\hline Área alagada de reservatório de usinas hidrelétricas autorizada pelo Poder Público & 08 & 1 & \\
\hline Área tributável (01-02-03-04-05-06-07-08) & 09 & $1|7| 8$ & \\
\hline Área ocupada com benfeitorias úteis e necessárias destinadas à atividade rural & 10 & 1 & \\
\hline Área aproveitável $(09-10)$ & 11 & $1,7,5$ & \\
\hline
\end{tabular}


11. DISTRIBUIÇÃO DA ÁREA UTILIZADA NA ATIVIDADE RURAL

\begin{tabular}{|c|c|c|c|}
\hline Área de produtos vegetais & 12 & 17,5 & 9 \\
\hline Área em descanso & 13 & 1 & 7 \\
\hline Área de reflorestamento (essências exóticas ou nativas) & 14 & 1 & 5 \\
\hline Área de pastagem & 15 & $1|4| 0,0$ & 3 \\
\hline Área de exploração extrativa & 16 & 1 & 1 \\
\hline Área de atividade granjeira ou aqüícola & 17 & $\perp$ & 8 \\
\hline Área de frustração de safra ou destruição de pastagem por calamidade pública & 18 & 1 & 6 \\
\hline Área utilizada na atividade rural $(12+\ldots+18)$ & 19 & $1,4,7,5$ & 4 \\
\hline
\end{tabular}

14. CÁLCULO DO VALOR DA TERRA NUA

\begin{tabular}{|l|c|c|c|}
\hline Valor total do imóvel & 27 & $\mid 2,5,1,6,9,0,0,0$ & 6 \\
\hline Valor das construções, instalações e benfeitorias & 28 & $|5,0| 0,0,0,0,0$ & 4 \\
\hline Valor das culturas, pastagens cultivadas e melhoradas e florestas plantadas & 29 & $|, 4,2| 0,0,0,0,0$ & 2 \\
\hline Valor da terra nua (27-28-29) & 30 & $|1,5,9| 6,9,0,0,0$ & 9 \\
\hline
\end{tabular}

15. CÁLCULO DO IMPOSTO

\begin{tabular}{|c|c|c|c|}
\hline Valor da terra nua tributável (campo $09 \div$ campo 01 ) $x$ campo 30 & 31 & $\mid 1,2,4,3,0,2,6,0$ & 7 \\
\hline Alíquota (veja a tabela abaixo) & 32 & $10,1 \mid 0 \%$ & 5 \\
\hline Imposto calculado (campo $31 \times$ campo 32 ) $\div 100$ & 33 & |||| $1,2,4,3,0$ & 3 \\
\hline $\begin{array}{l}\text { Imposto devido } \\
\text { Informe o maior valor entre o imposto calculado e o imposto mínimo }(R \$ 10,00)\end{array}$ & 34 & $|\quad| \mid 1,2,4,3,0$ & 1 \\
\hline
\end{tabular}

Fonte: Extraída de Brasil (2010).

O preenchimento do documento em seus itens 10 e 11 proporcionam o cálculo do coeficiente de aproveitamento do imóvel, do item 14 o cálculo do valor da terra nua, sobre o qual são avaliados o imposto devido e o item 15 indica como é feito o cálculo propriamente dito, levando em consideração a alíquota determinada pela classe na qual a área total do imóvel está incluída e o coeficiente de aproveitamento declarado.

\section{AS POSSIBILIDADES EM O MUNICÍPIO GERIR O CADASTRO DE TODO O TERRITÓRIO MUNICIPAL}

A partir de 1988, com a promulgação da Constituição Federal, uma mudança significativa foi imposta às municipalidades brasileiras. Junto com o aumento das responsabilidades, houve em alguns casos a redução nas receitas destinadas aos municípios. No caso do ITR, a arrecadação e fiscalização ficaram a cargo da União, que passou a destinar apenas $50 \%$ da receita do tributo aos municípios. No estado de Santa Catarina, segundo o 
Portal das Transferências Constitucionais, fora arrecadado no ano de 2015 o valor bruto de R\$ 97.233.356,95.

Em 28 de dezembro de 2005, a Lei 11.250 desencadeou um conjunto de ações que possibilitam ao município o retorno desse tributo, podendo ficar com até $100 \%$ da receita, desde que faça opção pela municipalização do ITR, sem modificar ou reduzir a atual alíquota. O município deve ainda, através da Normativa 643/06, cumprir exigências técnicas para a celebração de convênio, entre a Receita Federal e os municípios, as atribuições de fiscalização e cobrança do ITR.

a) Estão entre elas:

b) Possuir quadro de carreira de servidores com nível superior para executar o lançamento de créditos tributários;

c) Cumprir metas de fiscalização e arrecadação;

d) Possuir estrutura tecnológica compatível com as da Receita Federal;

e) Arcar com os custos do suporte tecnológico a ser contratado. Entretanto, somente através de uma outra instrução normativa, a n. 884/08, é que foram definitivamente estabelecidos todos os requisitos e condições necessárias para a celebração de tais convênios (BRASIL, 2011a).

Com este convênio, o município passa, a contar com uma gestão plena de seu território, sendo ferramenta necessária para a administração um cadastro técnico Multifinalitário. Destaca-se aqui a aplicabilidade do processo de descentralização e os instrumentos a serem utilizados no CTM, como descrito por Loch (2005):

a) Localização geográfica de todos os imóveis da cidade;

b) Ocupação ou finalidade de cada imóvel;

c) Uso atual do solo dentro de cada imóvel;

d) Declividade do solo;

e) Áreas em litígio entre imóveis confrontantes;

f) Delimitação de cada unidade imobiliária;

g) Estrutura fundiária e identificação das diferentes glebas;

h) Regularização dos títulos segundo as áreas;

i) Organização das comunidades segundo as glebas e, ou, bairros;

j) Base para implementação de infraestrutura;

k) Subsídios para a viabilização de projetos de engenharia; 
1) Avaliação do imóvel para desapropriação, visando obras públicas;

m) Facilidade para transações imobiliárias;

n) Base para valoração da terra.

Implantar algumas dessas aplicações é ter uma melhor visão da gestão do espaço territorial, aumentando a percepção cadastral dos gestores públicos. A descentralização da cobrança do ITR abre a possibilidade do incremento de receita, desde que sejam adotados os critérios de atualização e um sistema cadastral, diminuindo, assim, a disparidade dos sistemas declaratórios.

O Comitê Gestor do ITR, por meio da Resolução $n^{\circ}$ 2/2012, institui o Programa Omissos da Declaração do ITR para os municípios conveniados, com o objetivo de possibilitar o controle e o acompanhamento dos contribuintes omissos na entrega da declaração do ITR. O programa está em vigor desde 6 de março até o dia 20 de novembro de 2012.

O programa contém a relação dos contribuintes omissos das declarações anuais, possibilitando, assim, que os agentes municipais deem início à fiscalização do Imposto sobre a Propriedade Territorial Rural. Desde a municipalização do ITR em 2008, a gestão municipal pode fiscalizar as contribuições feitas ao ITR e arrecadar 100\% do imposto. Com o programa, as prefeituras poderão intimar os contribuintes omissos a apresentarem recibos de entrega das Declarações do ITR relativos aos exercícios de omissão ou o protocolo de entrega do Documento de Informação e Atualização Cadastral do ITR (Diac). A omissão da DITR será verificada em relação aos exercícios de 2007 a 2010.

O ponto negativo desta municipalização da receita do ITR, está no fato de que nem a própria Receita Federal, atualmente com sua estrutura e uma certa experiência, conseguiu elevar a arrecadação do ITR, colocando a cargo das administrações municipais tal incumbência. Atualmente, o quadro financeiro das prefeituras é preocupante, com poucos profissionais gabaritados para o cadastramento e fiscalização, mas o fato de que a prefeitura não poderá realizar renúncia fiscal eleva o grau de seriedade desse assunto, fazendo com que o gestor público responda por tal.

\section{CONSIDERAÇÕES FINAIS}

Mesmo com todas as mudanças pela qual passou a legislação do ITR ao longo dos anos, pouca efetividade ocorreu no sentido de melhorar os problemas administrativos e de 
arrecadação deste, havendo a necessidade de um disciplinamento do ITR em seu processo declaratório ou a nulidade desde método.

Passando sua competência de fiscalização, ao poder municipal, com seu setor de cadastro, possibilitando cadastrar a área rural e a incluir no seu sistema de informações geográficas.

A fiscalização com a finalidade de incremento de renda municipal fará com que irregularidades como a do sistema declaratório e ocupação de áreas devolutas aos poucos acabem em nosso país.

\section{REFERÊNCIAS}

AGEFIS - Agência de Fiscalização. Mapa de combate a grilagem e ocupações irregulares do DF. Disponível em: <http://www.agefis.df.gov.br/>. Acesso em: 29 abr. 2016.

ARAUJO, Adolfo Lino de; OLIVEIRA, Francisco Henrique de; FRAGA, Angelo Martins; MENDES, Lucio. Vulnerabilidade do sistema declaratório para tributação da propriedade rural. V Simpósio Brasileiro de Ciências Geodésicas e Tecnologias da Geoinformação, Recife/PE.p.96-102, nov. de 2014.

BALATA, K. S. Imposto territorial rural, seu potencial, sua evasão, sua solução: Cadastro Técnico Rural Multifinalitário - CTRM. In: Congresso Brasileiro de Cadastro Técnico Multifinalitário e Gestão Territorial, 2, 1996, Florianópolis, Santa Catarina. Anais... Florianópolis: UFSC, 1996.

BRASIL. Receita Federal do Brasil. Disponível em: <http://idg.receita.fazenda.gov.br/acessorapido/tributos/itr>. Acesso em: 28 abr. 2016. Ministério da Política Fundiária e do Desenvolvimento Agrário. O livro branco de grilagem de terras no Brasil. Brasília: INCRA, 1999.

Secretaria da Receita Federal do Brasil. ITR - Imposto Sobre a Propriedade

Territorial Rural. Manual de Preenchimento da Declaração. SRFB: Brasília, 2010.

Secretaria da Receita Federal do Brasil. ITR Convênio, 2011. Disponível em: <http://www.receita.fazenda.gov.br/PessoaJuridica/ITRConvenios/2008/Legislacao> Acesso em: 3 maio 2016.

Secretaria da Receita Federal do Brasil. ITR, Perguntas e Respostas, 2017.

Disponível em: $<\quad$ http://idg.receita.fazenda.gov.br/orientacao/tributaria/declaracoes-edemonstrativos/ditr-declaracao-do-imposto-sobre-a-propriedade-territorial-rural/perguntas-erespostas-itr/perguntas-e-respostas-itr-2017-v-1-0-11082017.pdf> Acesso em 05 abril de 2018.

INCRA - Instituto Nacional de Colonização e Reforma Agrária, 2016. Disponível em: <INCRA - http://www.incra.gov.br/estrutura-fundiaria/regularizacao-fundiaria/certificacaode-imoveis-rurais $>$. Acesso em: 4 maio 2016.

LOCH. C; Cadastro Técnico Multifinálitário: Instrumento de Política Fiscal e Urbana. In: ERBA, DIEGO ALFONSO. Cadastro Multifinalitário como instrumento da política fiscal e urbana. Rio de Janeiro: Ministério das Cidades, 2005, p76-77.

Carlos; ERBA, Diego Alfonso. Cadastro técnico multifinalitário: rural e urbano. Cambridge, MA: Lincon Institute of Land Policy, 2007 ${ }^{\mathrm{a}}$, p18.

.A realidade do Cadastro Técnico Multifinalitário no Brasil. Anais XIII Simpósio Brasileiro de Sensoriamento Remoto, Florianópolis, Brasil, INPE, p. 1281-1288, $2007 \mathrm{~b}$. 
TCU - Tribunal de Contas da União. Representação com pedido de medida cautelar. Indícios de irregularidades na seleção de beneficiários do Programa Nacional de Reforma Agrária. Disponível em: <portal.tcu.gov.br/lumis/portal/file/fileDownload.jsp?fileId...inline=1>. Acesso em: 3 maio 2016.

REYDON, B. P.; ROMEIRO, A.; PLATA, L.E.A.; SOARES, M. Preço elevado e o ITR. In: REYDON, B. P.; CORNÉLIO, F.N.M. (Orgs.). Mercado de Terras no Brasil: Estrutura e Dinâmica. Brasília, DF: MDA/NEAD, NEAIE/UNICAMP, 2006, p155-179. (NEAD Debate; 7).

VILARINHO, C. R. O. O Imposto Territorial Rural (ITR) No Brasil. 1989. 258 f. Tese (Mestrado em Economia) - Instituto de Economia, UNICAMP, Campinas, 1989

Web Carta Beta, IBGE. Disponível em: <http://www.ibge.gov.br/webcart/default.php>. Acesso em: 3 maio 2016. 